\title{
Long-term retention of a conditioned taste aversion in preweanling and adult rats
}

\author{
P. A. STEINERT, R. N. INFURNA, and N. E. SPEAR \\ State University of New York at Binghamton, Binghamton, New York 13901
}

\begin{abstract}
The retention and extinction of a conditioned taste aversion after either short (6-day) or long (60-day) intervals was investigated in preweanling (18-day-old) and adult rats. Taste-only and illness-only control conditions were employed, as were variations in the concentration of the US (holding $\mathrm{LiCl}$ amount constant). Results indicated that after the short retention interval, retention of the taste aversion was equivalent for both ages. After the long interval, however, the 18-day-old rats exhibited significantly weaker taste aversion than their adult counterpartsinfantile amnesia. Manipulation of US concentration had no effect on the magnitude of the taste aversions for either age or retention interval. The results are discussed in terms of their implications for infantile amnesia and general laws of learning.
\end{abstract}

Immature animals forget at a faster rate than do more mature animals (for reviews, see Campbell \& Coulter, 1976; Campbell \& Spear, 1972; Spear, $1978,1979)$, and this probably is also true for humans (Cohen \& Gelber, 1975; Levy, 1960; Pancratz \& Cohen, 1970). This accelerated rate of forgetting by younger organisms has been termed infantile amnesia. However, some recent evidence suggests that less infantile amnesia may occur when the information to be retained involves a particular class of events that may constitute a "highly prepared" association (Coulter, Collier, \& Campbell, 1976; Spear, 1978). Ontogenetic studies of conditioned taste aversion (Campbell \& Alberts, 1979; Klein, Mikulka, Domato, \& Hallstead, 1976) provide some of the more convincing of this evidence.

While long-term retention of taste-illness associations by adults is excellent (Biederman, Milgram, Heighington, Stockman, \& O'Neil, 1974; Dragoin, Hughes, Devine, \& Bentley, 1973), the data with respect to immature organisms are mixed. Specifically, Klein et al. (1976), using postweanling rats (23-dayold), and Campbell and Alberts (1979), who used preweanling (18-day-old) infant rats, have demonstrated retention equivalent to that of adults over retention intervals of 28 and 56 days. However, with rat pups 10 and 12 days of age, Campbell and Alberts (1979) did find poorer retention across long intervals. Both of these studies used $\mathrm{LiCl}$ as the unconditioned stimulus (US) and employed a singlebottle testing procedure. The data obtained with

Preparation of this article was supported by grants from the National Science Foundation (BNS 74-24194 and BNS 78-02360) to the third author. We thank Norman Richter for technical advice and assistance and Teri Tanenhaus for preparation of the manuscript. Requests for reprints should be sent to Norman E. Spear, Department of Psychology, State University of New York at Binghamton, Binghamton, New York 13901. these procedures suggest that, by 18 days of age, rat pups have attained adult levels of retention for a taste-illness association. In contrast to the findings of Campbell and Alberts (1979), Ader and Peck (1977) and Peck (Note 1) have reported relatively poor retention of an early (21-day-old rat pup) taste-illness experience over a 60-day interval. These studies employed cyclophosphamide as the US and used both single-bottle and preference tests. Further complications arise from the fact that none of the above studies included all control conditions necessary to determine the nonassociative influence of early experience with poisons or tastes on subsequent adult taste preference.

In view of the bulk of data substantiating the phenomenon of infantile amnesia in a variety of aversive (Campbell \& Campbell, 1962; Feigley \& Spear, 1970; Kirby, 1963; Misanin, Chubb, Quinn, \& Schweikert, 1974; Smith, 1968) and appetitive paradigms (Campbell, Jaynes, \& Misanin, 1968), it is of theoretical importance to investigate the generalizability of infantile amnesia with respect to taste aversion learning. The present experiment was, therefore, designed to compare the retention of taste aversions by mature and immature organisms, employing the necessary control conditions.

Because the dosage of $\mathrm{LiCl}$ and the temporal distribution of the US used by Campbell and Alberts (1979) varied among subjects (pups and adults were given 18 -h access to fluids containing either $.12 \mathrm{M} \mathrm{LiCl}$ or a $.12 \mathrm{M} \mathrm{NaCl}$ solution), the US ( $\mathrm{LiCl}$ ) parameter of concentration was manipulated in the present study. While the concentration of a $\mathrm{LiCl}$ solution (holding amount of $\mathrm{LiCl}$ constant) has been reported in adults to have no systematic effect on the magnitude of the illness-induced taste aversion (Nachman \& Ashe, 1973), the absence of such an effect may have been masked by either floor effects or the use 
of a single one-bottle test day. That is, the use of a more sensitive measure (two-bottle extinction testing) may have revealed US concentration effects. There are indirect data from studies using psychoactive compounds to suggest that the duration of the US may have systematic effects on the formation of a conditioned taste aversion (Cappell \& LeBlanc, 1977; Coussens, 1974). Specifically, drugs of sustained duration were found to increase the subsequent magnitude of the taste aversion. Therefore, use of a dilute solution of $\mathrm{LiCl}$ (which, due to its greater volume, may prolong absorption time and therefore duration) may then be expected to produce a stronger taste aversion when assessed by preference testing.

\section{METHOD}

\section{Subjects}

The subjects were 110 male and female preweanling rats (17 days of age) and 106 adult male and female ( $90-130$ days of age at the beginning of the experiment) Sprague-Dawley derived rats. All subjects were born and maintained in our breeding colony at the State University of New York at Binghamton. The animals were maintained on ad-lib food and water unless otherwise specified. The subjects were housed with their parents and conspecifics within standard maternity cages until Postnatal Day 21 (for adults) or Postnatal Day 24 (for preweanlings on long-term retention), when they were weaned and housed in groups of the same sex in wire cages. All subjects were maintained within the same vivarium, with a 16-h light, 8-h dark cycle with light onset at $0600 \mathrm{~h}$. Experimental manipulations were conducted between 0900 and $1300 \mathrm{~h}$.

\begin{abstract}
Apparatus
Preweanlings were given access to fluids through drinking bottles graduated to $.1 \mathrm{ml}$ and with a $10-\mathrm{ml}$ capacity (described by Infurna, Steinert, \& Spear, 1979). They gained access to the fluids through standard metal drinking spouts identical to those employed in the home cage. For adults, $100-\mathrm{ml}$ drinking bottles, graduated to $1 \mathrm{ml}$ and with ball-bearing Wahmann spouts to minimize spillage, were used. Adults were adapted to these devices by being permitted to consume their ad-lib daily water intake through them for 5 days prior to any experimental measurement. For both preweanlings and adults, the drinking devices provided an extremely sensitive index of fluid consumption, and spillage did not occur in any detectable amount.
\end{abstract}

\section{Design and Procedure}

The between-group factors were age (preweanling or adult), retention interval (6 or 60 days), and treatment (CS-only, two US-only, and two CS-US groups), varied orthogonally. Within these 20 groups, 3 extinction, two-bottle preference test days comprised the within-subjects factor.

For preweanlings, litters were assigned randomly to retention intervals; treatments were assigned randomly within litters. The same was true for adults within a gang cage. In this way, the subjects would not be disturbed during the retention interval. The number of subjects per group varied between 10 and 12 .

For all preweanlings, on Postnatal Day 17 both parents were removed from their maternity cage and housed in another cage with ad-lib access to food and water. Each pup was then placed individually into a single wire-mesh cage for a 1-h familiarization period, during which no access to fluids was available. Following this familiarization, the pups were returned to their maternity cage and water deprived for the following $22 \mathrm{~h}$. On Day 18, the conditioning day, the pups were again placed into the wire-mesh cages and given $1 \mathrm{~h}$ access to a single bottle containing either a $15 \%$ sucrose solution or tap water, according to their assigned group. The subjects were then weighed and given an immediate ip injection of physiological saline, .15 M LiCl $(20 \mathrm{cc} / \mathrm{kg})$, or $3.0 \mathrm{M} \mathrm{LiCl}(1 \mathrm{cc} / \mathrm{kg})$, according to their assignment, and placed back into their wire-mesh cages. While both these $\mathrm{LiCl}$ injections are equal to a $3.0 \mathrm{MEq} \mathrm{LiCl}$ dose, one $(.15 \mathrm{M})$ is more diluted than the other $(3.0 \mathrm{M})$. In sum, the five treatment groups were sucrose-saline, sucrose-.15 M LiCl, sucrose-3.0 M LiCl, water$.15 \mathrm{M} \mathrm{LiCl}$, and water-3.0 M LiCl. One hour after the final injection, all subjects were returned to their maternity cages with both parents and given ad-lib access to food and water.

For the 6-day retention groups, on the 5th day after the conditioning day, the parents were removed from the maternity cages and the pups were placed on a water-deprivation regimen. After $23 \mathrm{~h}$ of water deprivation, the pups (now 24 days of age) were placed into the wire-mesh cages and given a $1-h$, two-bottle (sucrose vs. water) test, Test Day 1 . The subjects were then water and parentally deprived for 2 additional days, during which additional extinction tests were conducted. For the 60-day retention group, on the 6th day following the conditioning day, the subjects were weaned and housed in gang cages by sex until 53 days later. Now, as adults, these subjects were water deprived for $23 \mathrm{~h}$ and given a 1-h preference test (sucrose vs. water). Again, the subjects were water deprived and then given 2 days of extinction testing.

For subjects conditioned as adults, all the procedures were the same as for the preweanlings, except for references to the maternity cage.

\section{RESULTS}

The amount of sucrose consumed on the conditioning day prior to injection did not differ between treatment groups within each age (all Fs $<1$ ). Preweanlings, as expected, drank less (mean $=1.61 \mathrm{ml}$; $\mathrm{SEM}=.15$ ) of the sucrose solution than did adults (mean $=10.49 \mathrm{ml}$; SEM $=1.52$ ). However, the ratio of sucrose intake to body weight on the conditioning day for preweanling and adult subjects was proportional, suggesting that, relative to body weight, the subjects had consumed equivalent volumes. (Mean preweaning weight $=33 \mathrm{~g}$, mean adult weight $=$ $304 \mathrm{~g}$, yielding intake/body weight ratios of .05 and .04. Due to an oversight, the adult weights for 26 of the 106 adults were not recorded and were therefore not included in this average.)

Because preweanling and adult rats differ in the amount of fluid they consume, conditioned aversions were evaluated on the basis of a measure of relative preference for sucrose solution compared with water. However, similar effects of age and retention interval occurred in terms of either the preference index or absolute intake of the sucrose solution.

\section{Analysis of Sucrose Preference on Test Day 1}

A sucrose preference score (sucrose intake $\div$ sucrose + water intake) was computed for each subject based on its Test Day 1 two-bottle consumption. These data were analyzed by an overall 2 by 2 by 2 by 5 analysis of variance (ANOVA), with Age at the time of conditioning (preweanling or adult) by Retention 
Interval (6 or 60 days) by Sex (male or female) by Group (sucrose-saline, sucrose-.15 $\mathrm{M} \mathrm{LiCl}$, sucrose3.0 $\mathrm{M} \mathrm{LiCl}$, water-.15 $\mathrm{M} \mathrm{LiCl}$, water- $3.0 \mathrm{M} \mathrm{LiCl}$ ) as the between-subjects variables. (Sex was never found to be a significant factor, either as a main effect or in any interaction, and therefore this variable was not considered further.) The overall analysis revealed a significant Age by Retention Interval by Group interaction $[F(4,176)=2.76, p<.025]$. The procedures recommended by Keppel (1973) were employed to assess significant interaction effects. In order to determine whether, within the Group factor, both control groups (sucrose-saline, water-.15 M LiCl, and water-3.0 $\mathrm{M} \mathrm{LiCl}$ ) and experimental groups (sucrose-.15 M LiCl, sucrose-3.0 M LiCl) contributed to this higher order interaction, separate (Age by Retention Interval by Group) analyses were performed for the control and experimental groups. In neither of these separate analyses did the Group variable attain significance, either as a main effect or as an interaction. This suggests that, for the overall analysis, the locus of the Group effect was a difference between the control and experimental groups. That is, relative to the control groups, all experimental groups exhibited a significantly attenuated preference for the sucrose solution previously paired with poison. Lack of significant Group effects among either the control or experimental groups demon-

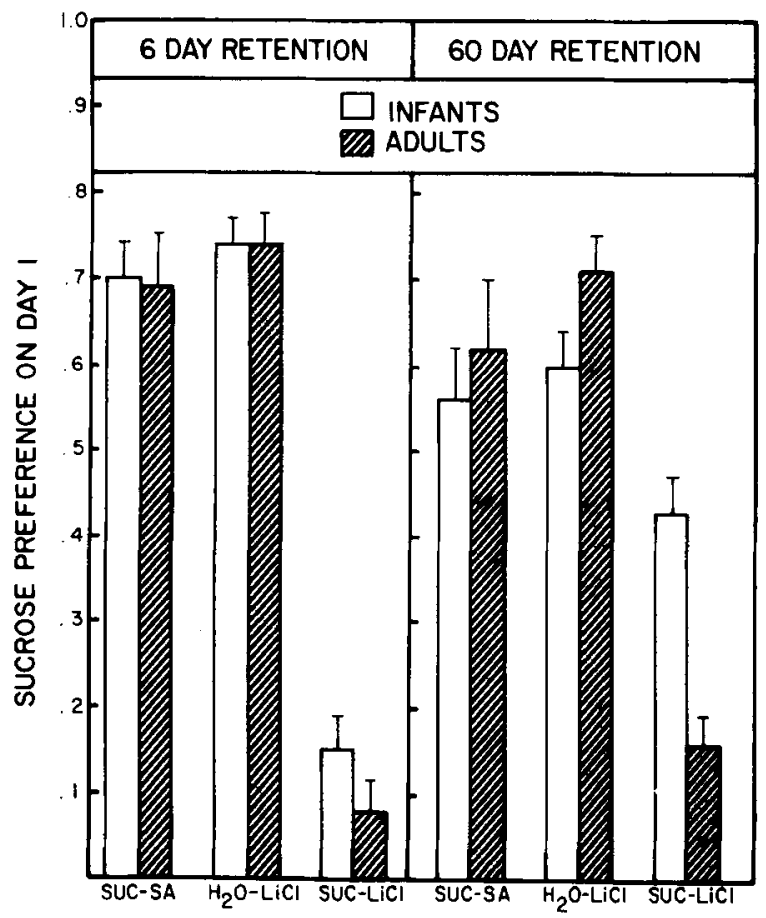

Figure 1. Test Day 1 means and standard errors of sucrose preference for preweanlings (open) and adults (shaded) for treatment groups collapsed across $\mathrm{LiCl}$ (US) concentration following retention intervals of 6 days (left panel) and 60 days (right panel). strates further that the manipulation of US concentration did not produce any significant differences in sucrose preference. Figure 1 presents the sucrose preference data of Test Day 1 for all groups collapsed across US intensity. These separate analyses suggested also that the locus of the Age by Retention Interval interaction was within the experimental groups alone $[\mathrm{F}(1,176)=6.76, \mathrm{p}<.01]$. More specifically, while the taste aversions exhibited by preweanling and adult rats did not differ in magnitude after the 6-day retention interval $[F(1,176)=2.51]$, preweanlings exhibited significantly weaker taste aversions than did adults following a 60 -day retention interval $[\mathrm{F}(1,176)=4.62, \mathrm{p}<.05]$.

The lack of a difference between infant and adult CS-US groups after the 6-day retention interval was also supported by the results of a t test on these data $[\mathrm{t}(43)=1.76]$. In addition, using the same parameters as the present experiment, Steinert, Infurna, Jardula, and Spear (1979) found that after a 6-day retention interval there was no difference in the magnitude of the taste aversions exhibited by preweanling and adult rats for any of three concentrations of sucrose solution $(3.4 \%, 15 \%, 34 \%)$.

Analysis of the experimental groups within each Age revealed that the taste aversions of preweanling infant rats were significantly weakened by the long retention interval $[F(1,176)=28.36, p<.001]$, but this long retention interval did not affect the magnitude of the taste aversion for adults $[F(1,176)=2.72]$. It is notable that the taste preferences exhibited by the pups given the CS-US pairing were still significantly different from controls after 60 days' $[F(1,176)$ $=11.32, p<.001]$, suggesting some retention of the earlier taste-illness episode. These results confirm the basic effect of greater long-term forgetting by 18 day-old preweanlings than by adults-infantile amnesia.

The separate analysis of the control groups' Test Day 1 sucrose preference scores revealed a significant main effect for retention interval $[\mathrm{F}(1,176)=8.67$, $p<.01]$. Overall, sucrose preference among the control groups decreased as retention interval increased. No other main effects or interactions attained significance.

In summary, the analysis of the Test Day 1 sucrose preference scores indicated that following a short (6-day) retention interval, preweanling and adult rats did not differ in preference for a taste previously paired with poison. This implies that acquisition of the taste-illness did not differ between age groups. However, when a longer (60-day) interval separated conditioning and testing, the decline in magnitude of the taste aversion was greater for the younger rats.

It should be emphasized that, in general, these conclusions were the same when absolute intake of sucrose solution was used as the dependent measure (see Figure 2). 


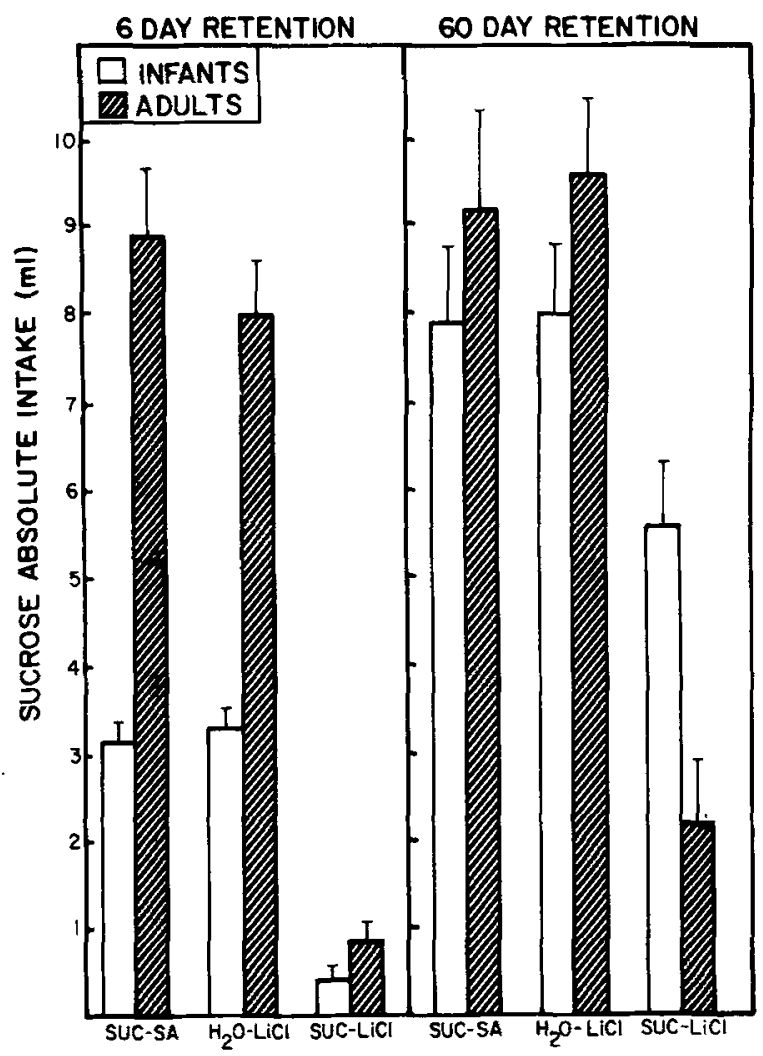

Figure 2. Test Day 1 means and standard errors of absolute sucrose intake for preweanlings (open) and adults (shaded) for treatment groups collapsed across $\mathrm{LiCl}$ concentration following retention intervals of 6 days (left panel) and 60 days (right panel).

\section{Analysis of Sucrose Preference Across Test Days}

An overall mixed model ANOVA was performed on the sucrose preference scores. This analysis was a 2 by 2 by 5 by 3 , where Age at the time of conditioning (preweanling or adult) by Retention Interval ( 6 or 60 days) by Group (sucrose-saline, sucrose-.15 M LiCl, sucrose-3.0 M LiCl, water-.15 $\mathrm{M} \mathrm{LiCl}$, water-3.0 M $\mathrm{LiCl}$ ) were the between-subjects factors and Days (extinction preference testing) was the within-subjects factor. As with Test Day 1, sucrose preference data, the higher order interaction of Age by Retention Interval by Group attained significance $[F(4,196)=2.90$, $\mathrm{p}<.025]$. In addition, both Age by Retention Interval by Days and Age by Group by Days attained significance $[F(2,392)=3.33, p<.05$, and $F(9,392)$ $=2.30, \mathrm{p}<.025$, respectively] .

In order to investigate the locus of the Age by Retention Interval by Group interaction across all Test Days, separate analyses were again performed for the control and experimental groups. These analyses again suggested that the only Group effect was the differences between the control and experimental groups. The lack of a Group effect again suggests that US concentration had no effect on the magnitude of the taste preference. Therefore, US concentration had no significant effect on either the acquisition or retention of the taste-illness experience as measured by both Test Day 1 sucrose preference and extinction across test days. Figure 3 represents all groups across days, collapsed across US concentration.

The separate analysis of the experimental groups alone revealed a significant triple interaction, Age by Retention Interval by Days $[F(2,392)=4.85, p<.01]$. The locus of the interactive effect of retention interval in this triple interaction appeared to reside within the preweanlings. That is, for preweanlings, but not for adults, there was a significant interaction between Retention Interval and Test Days $[F(2,392)=4.40$, $\mathrm{p}<.025]$. However, before concluding that extinction was faster after the 60-day retention interval than after the 6-day retention interval in preweanlings but not in adults, the effect within the experimental groups must be viewed in relation to that within the control groups. Because preferences tended to stabilize by the 2 nd extinction day, only the first 2 days of extinction testing are considered for this analysis. Although the effect of retention interval did interact with that of test days for preweanlings but not adults, this was true for the US-only (control) groups as well as the CS-US (experimental) groups $[F(1,84)=4.81, p<.025]$. That is, for preweanlings,

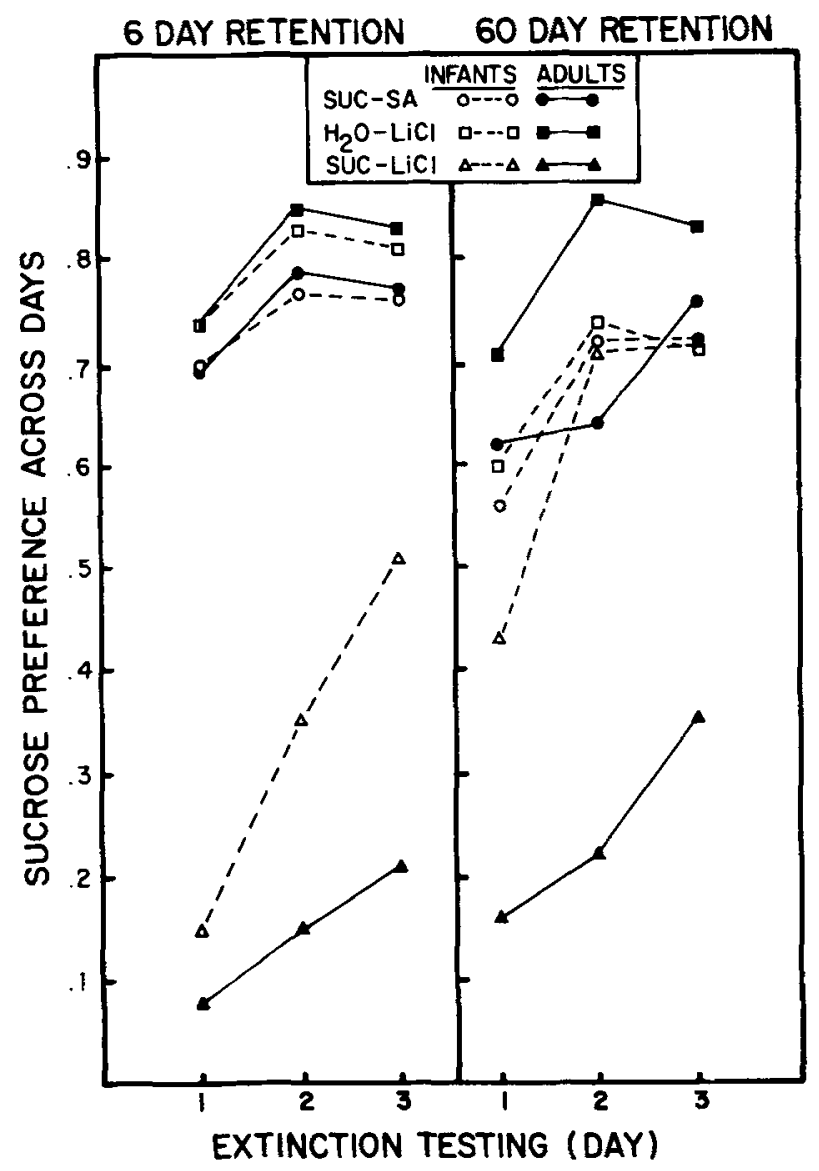

Figure 3. Mean sucrose preference for preweanlings (open) and adults (closed) across test days for treatment groups collapsed across $\mathrm{LiCl}$ concentration. 
but not for adults, the interpolation of a long retention interval increased the slope of the extinction curves if the US had been experienced, regardless of the CS-US pairing. Such a finding precludes the conclusion that, for preweanlings, extinction of the learned association was faster after 60 days than after 6 days. It should be emphasized, however, that the CS-US groups differed significantly from the USonly groups $[F(1,84)=14.45, p<.001]$, even though the slopes of their test scores were parallel across days. The overall increase in the slopes of the longterm retention data for preweanlings may represent some additional nonassociative factor that operates when organisms are tested as adults but conditioned as preweanlings.

With respect to the simple Age by Days interaction effect within the experimental groups, subsequent analyses suggested that presentation of sucrose solution across days did not increase the adults' sucrose preference as much as it did the preference of the subjects conditioned as preweanlings [for the 6-day interval, $F(2,392)=8.19, \mathrm{p}<.001$; for the 60 -day interval, $F(2,392)=9.30, p<.001]$. Viewing the 6-day retention interval data in the left panel of Figure 3, it can be seen that the curves diverge across days as a function of age. Since preweanling and adult rats demonstrated equivalent retention on Test Day 1, these curves represent differential rates of extinction. An analysis of linear trends on these data revealed differential age-dependent linear trends $[F(1,44)=136, p<.001]$, verifying the above interpretation. Age-dependent differential extinction rates may reflect a variety of phenomena. For example, as suggested by Berk, Vigorito, and Miller (1979), extinction may be construed as a situation producing interference effects due to similarity to conditioning procedures. Differential extinction rates may then reflect greater susceptibility to interference among immature organisms relative to more mature ones.

The 60-day retention interval data are depicted in the right panel of Figure 3. Since, at this point, preweanlings had forgotten more of the taste-illness experience than had adults, as assessed by their Test Day 1 sucrose preference scores, nothing can be stated as regards differential rates of extinction after the 60-day interval.

The separate analysis on the control groups' sucrose preference across days again revealed a significant main effect only of retention interval on performance $[F(1,196)=5.64, p<.025]$. That is, the interpolation of a long retention interval generally decreased sucrose preference.

In summary, the analysis of sucrose preference across days did not detect any effects of US concentration. Also, within a retention interval, control groups did not differ. In addition, the slopes of the extinction curves for all groups of preweanlings were steeper after 60 days than after 6 days. For experi- mental groups, preweanlings were found to extinguish faster than adults after the 6-day retention interval, but interpretation of their differential rates of extinction after the 60-day retention interval is difficult due to the initial differences in Test Day 1 sucrose preferences. Finally, for both ages, it must be concluded that rate of extinction was unaffected by length of the retention interval.

\section{DISCUSSION}

While previous research has reported nearly perfect retention of a taste-illness experience by young organisms (Campbell \& Alberts, 1979; Klein et al., 1976), these experiments did not include potentially important control conditions (e.g., US-only groups) and, in some cases, lacked specification of potentially significant parameters (e.g., temporal distribution of the US). In contrast to the data from these experiments, the present results argue against the hypothesis that certain associations (specifically, taste-illness experiences) are protected from the processes producing infantile amnesia. That is, while the Test Day 1 preference measure for preweanling and adult rats following the 6-day retention interval indicated equivalent acquisition of a taste aversion, long-term retention of the taste aversions by subjects conditioned when 18 days old was significantly poorer than for adults. Preweanlings forget more than do adults as a function of a long retention interval, for conditioned taste aversions as well as many other tasks.

This finding may be related to data demonstrating that, in comparison with adults, preweanlings show greater attenuation of their conditioned taste aversions as a function of the length of time interpolated between a taste and subsequent poisoning (Steinert et al., 1979). Accelerated rates of forgetting by immature organisms are found in the taste aversion task both during the acquisition of an association and following the learning of an association.

That the long-term retention deficit shown by preweanling rats represents differential rates of forgetting and not differential degrees of original learning is difficult to substantiate conclusively. Could it be that subjects conditioned as adults formed stronger taste-illness associations as a function of better developed perceptual systems, allowing for a clearer differentiation between the experimental environment and the home environment? This seems unlikely, since Infurna, Steinert, and Spear (1979) found, utilizing the same age, CS, and US dosage, that preweanlings are at least as sensitive as adults to the context at the time of conditioning. It is possible that the magnitude of the US (illness) differed as a function of maturity, thereby producing differential degrees of original learning. However, parametric studies designed to evaluate the influence of reinforcer magnitude (shock intensity and duration) on 
infantile amnesia have reported retention deficits irrespective of the reinforcer magnitude (Feigley \& Spear, 1970; Nagy, 1976), a finding replicated here in terms of US concentration. While similar studies that should directly assess these relationships with respect to toxicosis are needed, preliminary data from our laboratory (Caza, Steinert, \& Infurna, Note 2) have suggested that preweanling rats are more susceptible to lower dosages of $\mathrm{LiCl}$ than are adults, suggesting perhaps that the effective US magnitude for a particular dosage is higher for infants than for adults.

The data obtained pertaining to US concentration support the previous work of Nachman and Ashe (1973) in that US concentration had no differential effect on the acquisition of a taste-illness experience. In addition, the present results extend the lack of a US concentration effect to the retention and extinction of a taste aversion, when preference scores serve as the dependent measures. These generalizations hold for both immature and mature organisms.

With reference to the control groups used in the present study, the extinction data demonstrated an age-dependent effect of the retention interval. That is, while within a retention interval condition the control groups were equivalent, across retention interval conditions significant differences were obtained for organisms treated as preweanlings. The slopes of the preference curves for preweanlings were steeper after 60 days than after 6 days. There are data to suggest that young organisms do not exhibit the neophobia response (Rusiniak, Cabral, \& Garcia, Note 3; Rusiniak, Palmerino, \& Cabral, Note 4), the construct used to describe decreased intake of a solution based on its novelty. The effect of retention interval on control groups treated as preweanlings could then reflect the absence vs. presence of the neophobic response by the 6-day vs. 60-day retention interval groups, respectively. Among adults, the neophobia response would not be expected to vary, and this is supported by the lack of an effect of retention interval on the control groups.

While it is clear from these data that preweanlings show more forgetting of a conditioned taste aversion than do adults as a function of length of the retention interval, it should be remembered that for adults, retention is nearly perfect. In fact, the slopes of the extinction curves across retention interval are very similar. It has been suggested, as a general proposition (Gleitman, 1971), that a characteristic of classical conditioning involving an aversive US is its unwavering retention among adult subjects. Support for this comes from studies utilizing CER (Hoffman, Feshler, \& Jensen, 1963) and conditioned suppression (Campbell \& Campbell, 1962), although support is lacking in terms of some other conditioning paradigms (Spear \& Parsons, 1976). The present data suggest that similarly maintained retention can be obtained when toxicosis is used as the motivating stimulus. In addition, the finding of similar extinction curves for adults irrespective of retention interval parallels the findings of Gleitman and Holmes (1967). In terms of a CER paradigm, Gleitman and Holmes found no long-term retention deficits and equivalent extinction curves for the short (1-day) and long (90day) retention interval conditions. Collectively, these findings suggest that the functions representing aversively motivated classically conditioned responses may act irrespective of the nature of the conditioned and unconditioned stimulus.

In summary, there are three major implications of the present study. First, the phenomenon of infantile amnesia among preweanling (18-day-old) rats is generalizable to taste aversion learning. Second, US concentration may not be a particularly important consideration for studies of taste aversion learning and retention. Third, taste-toxicosis memories parallel shock-motivated memories in a number of significant ways, thereby providing additional support for the generality of the laws of learning (cf. Logue, 1979; Revusky, 1977; Seligman, 1970).

\section{REFERENCE NOTES}

1. Peck, J. Acquisition and retention of an illness-induced taste aversion as a function of age in the rat. Paper presented at the meetings of the Eastern Psychological Association, New York, 1976.

2. Caza, P. A., Steinert, P. A., \& Infurna, R. N. Dose dependent circadian susceptibility indexed by taste aversion learning and retention in preweanling rats. Paper presented at the 50th annual meeting of the Eastern Psychological Association, Philadelphia, April 1979.

3. Rusiniak, K. W., Cabral, R. J., \& Garcia, J. Ontogeny of conditioned flavor aversions. Paper presented at the International Symposium on Developmental Psychology, Anaheim, California, 1977.

4. Rusiniak, K. W., Palmerino, C. C., \& Cabral, R. J. Effects of early nursing deprivation on neophobia and taste aversion learning. Paper presented at the Western Psychological Association meetings, Seattle, 1977.

\section{REFERENCES}

Ader, R., \& Peck, J. H. Early learning and retention of a conditioned taste aversion. Developmental Psychobiology, 1977, 10, 213-218.

Berk, A. M., Vigorito, M., \& Miller, R. R. Retroactive stimulus interference with conditioned emotional response retention in infant and adult rats: Implications for infantile amnesia. Journal of Experimental Psychology: Animal Behavior Processes, 1979, 5, 284-299.

Biederman, G. B., Milgram, N. W., Heighington, G. A., Stockman, S. M., \& O'Neill, W. Memory of conditioned food aversion follows a U-shape function in rats. Quarterly Journal of Experimental Psychology, 1974, 26, 610-615.

Campbell, B. A., \& Alberts, J. R. Ontogeny of long-term memory for learned taste aversions. Behavioral and Neural Biology, 1979, 25, 139-156.

Campbelt, B. A., \& Campbell, E. H. Retention and extinction of learned fear in infant and adult rats. Journal of Comparative and Physiological Psychology, 1962, 55, 1-8. 
Campbell, B. A., \& Coulter, X. Ontogeny of learning and memory. Cambridge: M.I.T. Press, 1976.

Campbell, B. A., Jaynes, J., \& Misanin, J. R. Retention of a light-dark discrimination in rats of different ages. Journal of Comparative and Physiological Psychology, 1968, 66, 467-472.

Campbell, B. A., \& Spear, N. E. Ontogeny of memory. Psychological Review, 1972, 79, 215-236.

Cappell, H., \& LeBlanc, A. E. Parametric investigations of the effects of prior exposure to amphetamine and morphine on conditioned gustatory aversion. Psychopharmacology, 1977, 51, 265-271.

Cohen, L. B., \& Gelber, E. R. Infant visual memory. In L. B. Cohen \& P. Salapatek (Eds.), Infant perception: From sensation to cognition (Vol. 1) Basic visual processes. New York: Academic Press, 1975.

Coulter, X., Collier, A. C., \& Campbell, B. A. Long-term retention of early Pavlovian fear conditioning in infant rats. Journal of Experimental Psychology: Animal Behavior Processes, 1976, 2, 48-56.

Coussens, W. R. Conditioned taste aversion: Route of drug administration. In J. M. Singh \& H. Lal (Eds.), Drug addiction: Neurobiology and influences on behavior (Vol. 3). Miami: Symposium Specialists, 1974.

Dragoin, W., Hughes, G., Devine, M., \& Bentley, J. Longterm retention of conditioned taste aversions: Effects of gustatory interference. Psychological Reports, 1973, 33, 511-514.

Feigley, D. A., \& Spear, N. E. Effect of age and punishment condition on long-term retention by the rat of active and passive avoidance learning. Journal of Comparative and Physiological Psychology, 1970, 73, 514-526.

Gle itman, H. Forgetting of long-term memories in animals. In W. K. Honig \& P. H. R. James (Eds.), Animal memory. New York: Academic Press, 1971.

Gleitman, H., \& Holmes, P. Retention of incompletely learned CER in rats. Psychonomic Science, 1967, 7, 19-20.

Hoffman, H. S., Fleshler, M., \& Jensen, P. Stimulus aspects of aversive controls: The retention of conditioned suppression. Journal of the Experimental Analysis of Behavior, 1963, 6, 575-583.

Infurna, R. N., Steinert, P. A., \& Spear, N. E. Ontogenetic changes in the modulation of taste aversion learning by home environmental cues. Journal of Comparative and Physiological Psychology, 1979, 93, 1097-1108.

KEPPEL, G. Design and analysis: $A$ researcher's handbook. Englewood Cliffs, N.J: Prentice-Hall, 1973.

KIRBY, R. H. Acquisition, extinction and retention of an avoidance response in rats as a function of age. Journal of Com- parative and Physiological Psychology, 1963, 56, 158-162.

Klein, S. B., Mikulka, P. J., Domato, G. C., \& Hallstead, C. Retention of internal experiences in juvenile and adult rats. Physiological Psychology, 1976, 5, 63-66.

LEvy, D. M. The infant's earliest memory of innoculation: A contribution to public health procedures. Journal of Genetic Psychology, 1960, 96, 3-46.

Logue, A. W. Taste aversion and the generality of the laws of learning. Psychological Bulletin, 1979, 86, 276-296.

Misanin, J. R., Chubb, L. D., Quinn, S. A., \& Schweikert, G. E. An apparatus and procedure for effective instrumental training of neonatal and infant rats. Bulletin of the Psychonomic Society, 1974, 4, 171-173.

Nachman, M., \& Ashe, J. H. Learned taste aversions in rats as a function of dosage, concentration, and route of administration of LiCl. Physiology \& Behavior, 1973, 10, 73-78.

NAGY, Z. M. Escape learning in infant mice as a function of drive levels and drive shift during acquisition. Developmental Psychobiology, 1976, 9, 389-399.

Pancratz, C. N., \& Cohen, L. B. Recovery of habituation in infants. Journal of Comparative and Physiological Psychology, 1970, 9, 208-216.

REvUSKy, S. Learning as a general process with an emphasis on data from feeding experiments. In N. M. Milgram, L. Krames, \& T. M. Alloway (Eds.), Food aversion learning. New York and London: Plenum Press, 1977.

Seligman, M. E. P. On the generality of the laws of learning. Psychological Review, 1970, 77, 406-418.

Smith, N. Effects of interpolated learning on the retention of an escape response in rats as a function of age. Journal of Comparative and Physiological Psychology, 1968, 65, 422-426.

SPEAr, N. E. The processing of memories: Forgetting and retention. Hilisdale, N.J: Erlbaum, 1978.

Spear, N. E. Experimental analysis of infantile amnesia. In J. F. Kihlstrom \& F. J. Evans (Eds.), Functional disorders of memory. Hillsdale, N.J: Erlbaum, 1979.

Spear, N. E., \& Parsons, P. Analysis of a reactivation treatment: Ontogeny and alleviated forgetting. In D. Medin, R. Davis, \& W. Roberts (Eds.), Coding processes in animal memory. Hillsdale, N.J: Erlbaum, 1976.

Steinert, P. A., Infurna, R. N., Jardula, M. F., \& Spear, N. E. Effects of CS concentration on long delay taste aversion learning in preweanling and adult rats. Behavioral and Neural Biology, 1979, 27, 487-502.

(Received for publication July 17, 1979; revision accepted February 19, 1980.) 